\title{
Técnica de incidente crítico e seu uso na Enfermagem: revisão integrativa da literatura
}

\author{
Critical incident technique and its Nursing use: an integrative literature review
}

Técnica del incidente crítico y su uso en Enfermería: revisión integrativa de la literatura

\author{
Luana Cássia Miranda Ribeiro', Adenícia Custódia Silva e Souza', \\ Regiane Aparecida dos Santos Soares Barreto', Heliny Carneiro Cunha Neves', Maria Alves Barbosa' \\ 'Universidade Federal de Goiás, Faculdade de Enfermagem, \\ Programa de Pós Graduação em Enfermagem. Goiânia-GO, Brasil
}

Submissão: 28-12-2010 Aprovação: 17-01-2012

\section{RESUMO}

Revisão integrativa da literatura realizada nas bases de dados LILACS, MEDLINE e SciELO no período de 2000 a 2010 , com os objetivos de sintetizar o conhecimento produzido nas pesquisas em enfermagem que utilizaram a técnica de incidente crítico e identificar o uso e a aplicabilidade dessa técnica como referencial metodológico. Os achados perfizeram um total de dezessete artigos científicos e demonstraram que o Brasil se destacou com 76,5\% de publicações. A análise e categorização, segundo os três elementos da técnica, ocorreram em 76,0\% dos artigos. A categoria "análise de iatrogenias" provocadas pelos profissionais de saúde se destacou quanto à utilização da técnica de incidente crítico. A revisão integrativa possibilitou a construção de uma síntese do conhecimento científico sobre essa técnica, além de demonstrar sua ampla contribuição para a melhoria da assistência de enfermagem e de saúde.

Descritores: Técnica de incidente crítico; Enfermagem; Pesquisa qualitativa.

\begin{abstract}
Integrative literature review conducted in the databases LILACS, MEDLINE and SciELO from 2000 to 2010 to synthesize knowledge produced in nursing studies using the critical incident technique and identify the use and applicability of this technique as methodological framework. A total of 17 papers were found and Brazil stood out with $76.5 \%$ of the studies. Analysis and characterization according to the three elements of the technique were identified in $76.0 \%$ of the papers. The category 'analysis of iatrogenic events' caused by health workers stood out in the use of the critical incident technique. The integrative review enabled to synthesize scientific knowledge on this subject and revealed its large contribution to the improvement of health and nursing care.
\end{abstract}

Key words: Critical incident technique; Nursing; Qualitative research.

\section{RESUMEN}

Revisión integrativa de la literatura, realizada en las bases de datos LILACS, MEDLINE y SciELO, en el periodo entre 2000 y 2010, con los objetivos de sintetizar el conocimiento producido en las investigaciones en Enfermería que utilizaron la técnica de incidente crítico e identificar el uso y la aplicabilidad de esta técnica como referencial metodológico. Los hallazgos totalizaron 17 artículos científicos y han demostrado que Brasil se ha destacado con el 76,5\% de las publicaciones. El análisis y la categorización según los tres elementos de la técnica ocurrieron en el 76,0\% de los artículos. La categoría "análisis de iatrogenias" provocadas por los profesionales de la salud se destaca en el uso de la técnica del incidente crítico. La revisión integrativa permitió la construcción de una síntesis de los conocimientos científicos sobre esta técnica, además de mostrar su amplia contribución a la mejora de la atención de enfermería y de la salud.

Palabras clave: Técnica de Incidente Crítico; Enfermería; Investigación Cualitativa. 


\section{INTRODUÇÃO}

O avanço da ciência e do desenvolvimento tecnológico é evidente em todas as áreas do conhecimento e a Enfermagem, inserida nesse contexto, tem buscado aprimoramento de suas ações investigativas fortemente influenciadas pelo ensino de pós-graduação stricto sensu. A pesquisa nessa área tem o desafio de produzir conhecimentos que tenham impacto na prática e subsidiem ações de cuidado baseadas em evidências científicas $^{(1-2)}$.

Para isso os pesquisadores da área tem se apropriado de referenciais teóricos e metodológicos que sejam capazes de produzir resultados que conduzam mudanças e qualifiquem as ações de enfermagem ${ }^{(2)}$. Dentre esses referenciais metodológicos, destaca-se a técnica de incidente crítico $(\mathrm{TIC})^{(3)}$ que consiste em uma forma de obtenção de dados qualitativos, utilizada nas últimas décadas na área da enfermagem, pela sua capacidade de acessar a subjetividade das pessoas que vivenciaram determinadas situações.

Esta técnica foi proposta por John C. Flanagan, como resultado de estudos no Programa de Psicologia da Aviação da Força Aérea dos Estados Unidos na II Guerra, em $1941^{(3)}$. A finalidade do referido programa era seleção e classificação dos envolvidos, determinando os motivos do fracasso na aprendizagem de vôo e apontando exigências críticas para tal atividade, desenvolvendo, a partir disso, um método de avaliação psicológica para os pilotos ${ }^{(4)}$. Os conceitos de Flanagan têm inspiração behaviorista e enfatizam o comportamento observável e a descrição operacional de uma determinada situação( ${ }^{(5)}$.

As pesquisas na área da saúde que utilizam a TIC, geralmente, buscam por situações comportamentais, como erros na assistência em saúde, avaliação de competência para alguma atividade e indicadores de qualidade na área da gestão(6-10). A aplicação da TIC permite captar fatores culturais, valores, experiências, sentimentos, emoções dos sujeitos que vivenciaram uma "situação", que originou um "comportamento" e uma "conseqüência", os três componentes fundamentais para se caracterizar o incidente crítico $^{(11)}$. Tais componentes também são utilizados como categorias para análise dos incidentes críticos, dando a esta técnica caráter de método de coleta e de análise de dados qualitativos em pesquisas ${ }^{(11)}$.

Um incidente é qualquer atividade humana observável que seja completa em si mesma para permitir inferências e previsões a respeito da pessoa que executa o ato. Para ser crítico o incidente deve ocorrer em uma situação onde o propósito ou intenção do ato pareça razoavelmente claro ao observador, onde suas consequências sejam suficientemente definidas para deixar poucas dúvidas no que se refere aos seus efeitos ${ }^{(3)}$.

A essência da TIC implica em solicitar ao observador ou aos sujeitos envolvidos numa determinada atividade, tipos simples de julgamentos ou relatos de situações e fatos. Para se obter bons resultados nas pesquisas e na coleta dos dados com a TIC, é importante que o pesquisador tenha clareza e precisão dos objetivos a serem alcançados na investigação ${ }^{(12)}$.

$\mathrm{Na}$ Enfermagem o uso da TIC permite identificar a perspectiva de pacientes, profissionais, familiares, estudantes, acerca de fatos significativos que envolvem o cuidado ${ }^{(5-6,13-16)}$, viabilizando o planejamento e reestruturação de ações com vistas à melhoria da qualidade da assistência ${ }^{(13)}$.

Para que determinado fato seja considerado um "incidente crítico" é fundamental a identificação de uma situação real, o comportamento e a consequência gerados a partir dela $a^{(11,17)}$. Entretanto, para o alcance satisfatório da técnica e, portanto, garantir o rigor metodológico para que as evidências sejam confiáveis, é necessária que a coleta, a organização e a análise dos dados sejam sistematizadas de modo a contemplar os componentes da TIC. Esse é o grande desafio do pesquisador que utiliza a técnica, pois desse processo se garante ou não a construção de conhecimento científico de maior confiabilidade. A qualidade da análise e discussão dos dados tem sido apontada como um ponto frágil na elaboração dos artigos científicos ${ }^{(18)}$.

A TIC tem sido utilizada para analisar aspectos subjetivos de comportamentos e de dinâmica de serviços e tem revelado, nas pesquisas que a utilizam, os níveis de exigência crítica necessários para as transformações requeridas. Contudo, há autores ${ }^{(19-20)}$ que só a utilizam como técnica para a coleta de dados e outros ${ }^{(21-28)}$ como referencial metodológico em todas as suas etapas, incluindo a análise dos dados.

Considerando o objetivo e o alcance da técnica, bem como sua complexidade, surgiu o interesse em se verificar a produção cientifica atual da Enfermagem que se baseia no uso da TIC como referencial metodológico. Por essa razão se propôs a realização de uma revisão integrativa de literatura considerando os últimos dez anos de publicações, a qual teve como objetivos sintetizar o conhecimento produzido nas pesquisas em enfermagem que utilizaram a técnica de incidente crítico e identificar o uso e a aplicabilidade dessa técnica como referencial metodológico.

\section{DELINEAMENTO METODOLÓGICO}

Revisão integrativa de literatura sobre artigos que utilizaram a técnica do incidente crítico como referencial metodológico. Esse tipo de revisão tem a finalidade de reunir e sintetizar resultado de pesquisa sobre um determinado tema, de maneira sistemática e ordenada, sendo um instrumento para o aprofundamento do conhecimento a respeito do tema investigado, permitindo a síntese de múltiplos estudos publicados e conclusões gerais a respeito de uma particular área de estudo ${ }^{(29)}$.

Para operacionalizar a revisão integrativa, foram desenvolvidas as seis etapas propostas por autores ${ }^{(29)}$. Inicialmente identificou-se o tema de interesse e a condução da pesquisa foi feita a partir das seguintes questões norteadoras: Quais artigos utilizaram a TIC como referencial metodológico? Como os pesquisadores em enfermagem que utilizam a TIC têm analisado os dados de observação da realidade?

A busca foi realizada nas bases de dados Literatura Latino-Americana e do Caribe em Ciências da Saúde (LILACS), Literatura Internacional em Ciências da Saúde (MEDLINE) e Scientific Electronic Library Online (SciELO), nos últimos dez anos, correspondendo ao período de 2000 a 2010. A escolha das bases de dados (LILACS, MEDLINE e SciELO) se deu em virtude de sua abrangência (nacional e internacional), e por serem consideradas referências na produção de 
conhecimento na área da saúde, além de permitirem o acesso a dados atualizados via internet.

Os critérios de inclusão utilizados na busca foram: artigos na íntegra on-line na área da enfermagem; nas línguas portuguesa, inglesa e espanhola; que utilizaram a TIC proposta por Flanagan $^{(3)}$ indexados nas bases de dados citadas, publicados no período de 2000 a 2010. Os critérios de exclusão foram: relatos de casos, artigos de revisão e reflexão, documentos oficiais, capítulos de livros, teses, dissertações, notícias editoriais e textos não científicos.
A busca foi realizada entre abril e outubro de 2010, orientada pelos descritores controlados e pesquisados nos Descritores em Ciências da Saúde (DeCS) da Biblioteca Virtual de Saúde (BVS): [técnica de incidente crítico] e [enfermagem], além das palavras-chaves: técnica do incidente crítico, "technical incident critical" e "nursing" visando abranger os artigos objeto desse estudo. Para garantir acesso ao maior número de artigos na íntegra utilizou-se o sistema de acesso livre aos periódicos CAPES.

\begin{tabular}{|c|c|c|}
\hline Bases de dados & [Descritores] e palavras-chave & N \\
\hline \multirow{3}{*}{ LILACS } & [Técnica de Incidente Crítico] and [Enfermagem] & 4 \\
\cline { 2 - 4 } & Técnica and do and incidente and crítico and enfermagem & 21 \\
\cline { 2 - 4 } & Technical and incident and critical and nursing & 78 \\
\hline \multirow{3}{*}{ MEDLINE } & [Técnica de Incidente Crítico] and [Enfermagem] & 0 \\
\cline { 2 - 4 } & Técnica and do and incidente and crítico and enfermagem & 22 \\
\cline { 2 - 4 } & Technical and incident and critical and nursing & 1 \\
\cline { 2 - 4 } & [Técnica de Incidente Crítico] and [Enfermagem] & 2 \\
\cline { 2 - 4 } & Técnica and do and incidente and crítico and enfermagem \\
\hline
\end{tabular}

Quadro 1 - Referências localizadas segundo base de dados, descritores e palavras-chaves. Goiânia, 2010.

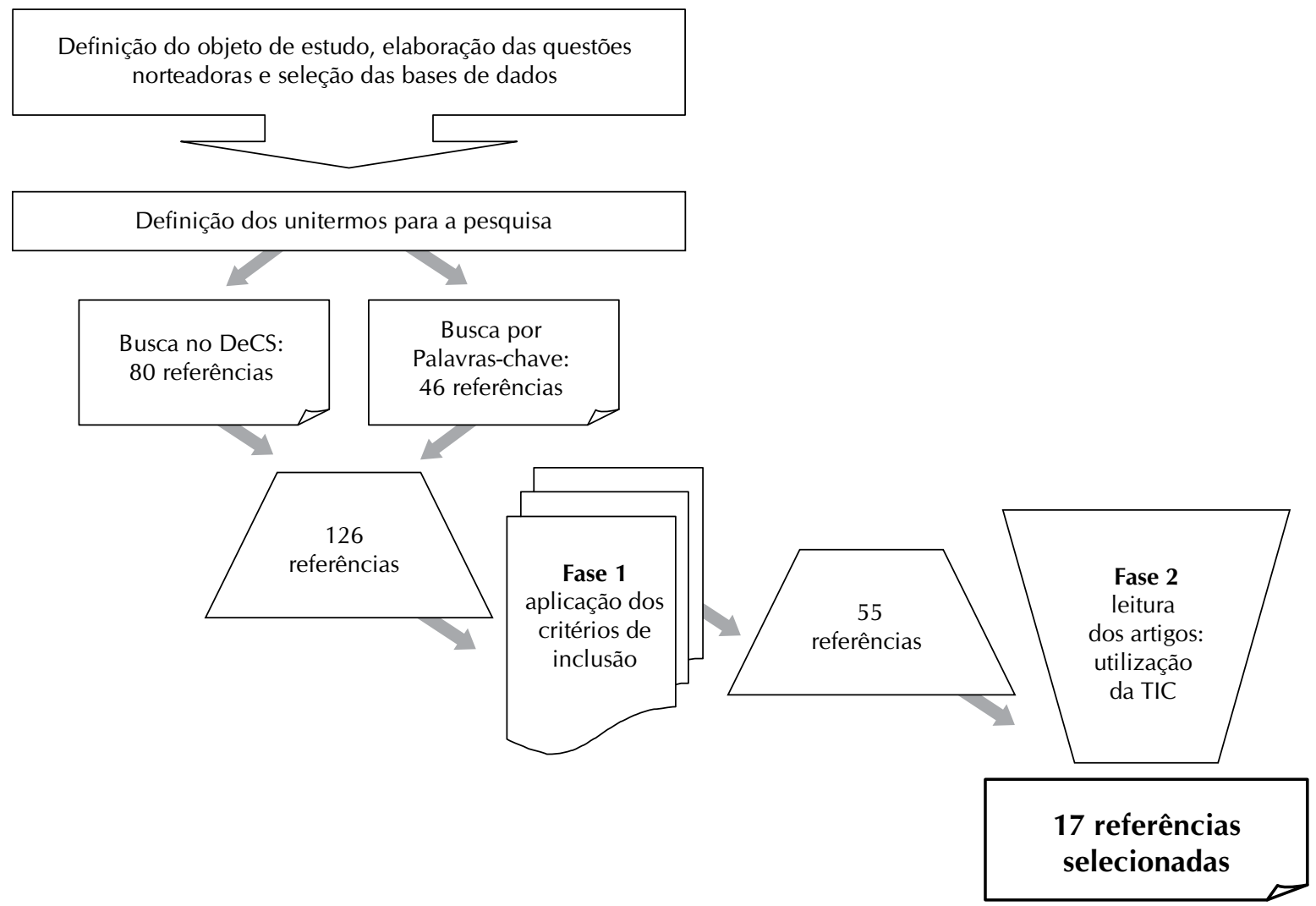

Figura 1 - Fluxograma de seleção dos artigos utilizados no estudo. Goiânia, 2010. 
A apresentação da amostra obtida nas bases de dados selecionadas de acordo com o cruzamento dos descritores controlados e palavras-chaves estão descritos no quadro 1.

A partir dos resultados da busca e obedecendo rigorosamente aos critérios de inclusão e exclusão apresentados, realizou-se a leitura exaustiva dos artigos, no intuito de verificar a sua adequação às questões norteadoras da investigação. $\mathrm{O}$ processo utilizado para delimitar os artigos que foram objeto de estudo na pesquisa foi sintetizado na figura 1 .

A análise dos dados foi realizada em duas etapas. Na primeira, foram identificados os dados de localização do artigo, autores, título, ano e país de publicação, bases de dados e periódicos. Após esse momento procedeu-se a segunda etapa, de análise propriamente dita, o conteúdo foi explorado por meio de revisão crítica atendendo aos critérios de elegibilidade, objetivos, processo analítico e resultados obtidos. As fortalezas e as fragilidades foram discutidas no decorrer do texto. A apresentação e discussão dos resultados obtidos foram feitas de forma descritiva, possibilitando a avaliação da aplicabilidade da revisão integrativa elaborada, de forma a atingir o objetivo desse método no presente estudo.

\section{RESULTADOS E DISCUSSÃO}

Após a busca utilizando os descritores e as palavras chave foram encontrados 129 artigos. Desse total, 25 foram na base de dados LILACS, 100 no MEDLINE e quatro no SciELO como pode ser observado no quadro 1. Desses, cinco artigos não foram selecionados por estarem em outros idiomas além dos determinados pelos critérios de inclusão, nove artigos não consistiram em artigos de pesquisa e 13 são de publicação antes do ano 2000, além de três artigos serem concomitantes em mais de uma base de dados. Trinta e três artigos não foram incluídos por não utilizarem utilizaram a TIC proposta por Flanagan, que foi determinado como critério de inclusão. $E$ ainda 49 artigos não foram disponíveis on line. Desse processo, foram selecionados para a amostra 17 artigos que atenderam a todos os critérios de elegibilidade.

\section{Caracterização dos estudos}

Os 17 artigos científicos incluídos no estudo foram apresentados na tabela 1, considerando sua distribuição ao longo dos anos e os periódicos em que foram publicados.

Os achados demonstraram que os anos mais predominantes de publicação foram 2000, 2002 e 2006, com três (17,6\%) artigos em cada, seguido de 2001, 2007 e 2008 com duas $(11,7 \%)$ publicações cada. Nos anos de 2004 e 2005 houve uma (5,9\%) publicação em cada ano e nos anos de 2003, 2009 e 2010 nenhuma publicação indexada.

Quanto aos periódicos houve predominância da "Revista Latino-americana de Enfermagem", com cinco (29,4\%) artigos nesse período, seguido da "Acta Paulista de Enfermagem" e "Revista da Escola de Enfermagem da USP", duas (11,7\%) publicações em cada; e nas demais, uma (5,9\%) publicação em cada.

Quanto às bases de dados em que as pesquisas foram indexadas: 12 (70,6\%) foram localizadas na LILACS, 4 (23,5\%)

Tabela 1 - Distribuição de artigos publicados sobre técnica de incidente crítico em enfermagem, por periódico e ano, no período de 2000 a outubro de 2010. Goiânia-GO, 2010.

\begin{tabular}{|c|c|c|c|c|c|c|c|c|c|c|c|c|}
\hline \multirow[t]{2}{*}{ Periódicos } & \multicolumn{11}{|c|}{ Ano de publicação } & \multirow[t]{2}{*}{ Total } \\
\hline & 2000 & 01 & 02 & 03 & 04 & 05 & 06 & 07 & 08 & 09 & 2010 & \\
\hline Acta Paulista de Enfermagem & - & 1 & 1 & - & - & - & - & - & - & - & - & 2 \\
\hline Revista Medicina (Ribeirão Preto) & 1 & - & - & - & - & - & - & - & - & - & - & 1 \\
\hline Revista Latino-americana de Enfermagem & 1 & - & 1 & - & - & 1 & 1 & - & 1 & - & - & 5 \\
\hline International Journal of Nursing Studies & - & - & - & - & - & - & 1 & - & - & - & - & 1 \\
\hline Journal of Advanced Nursing & - & - & - & - & - & - & 1 & - & - & - & - & 1 \\
\hline Revista da Escola de Enfermagem da USP & 1 & - & - & - & - & - & - & 1 & - & - & - & 2 \\
\hline Revista Enfermagem UERJ & - & - & - & - & - & - & - & 1 & - & - & - & 1 \\
\hline Revista Ciência, Cuidado e Saúde & - & - & 1 & - & - & - & - & - & - & - & - & 1 \\
\hline Arquivos de Ciências da Saúde da UNIPAR & - & 1 & - & - & - & - & - & - & - & - & - & 1 \\
\hline Scandinavian Journal of Caring Sciences & - & - & - & - & - & - & - & - & 1 & - & - & 1 \\
\hline British Journal of Nursing & - & - & - & - & 1 & - & - & - & - & - & - & 1 \\
\hline Total & 3 & 2 & 3 & - & 1 & 1 & 3 & 2 & 2 & - & - & 17 \\
\hline
\end{tabular}


no MEDLINE e uma $(5,9 \%)$ no SciELO. No que se refere aos países de realização das 17 pesquisas encontradas e analisadas, $13(76,5 \%)$ foram desenvolvidas no Brasil, três $(17,6 \%)$ na Inglaterra e uma $(5,9 \%)$ na Suécia. Esses dados demonstraram a familiaridade dos pesquisadores brasileiros com a TIC, o que pode ser justificado pela influência de Dela Coleta, pesquisador que aplicou a técnica no Brasil, na década de 1970, na área de recursos humanos, visando recrutamento, seleção e treinamento de pessoal ${ }^{(30)}$ e sua aproximação e contribuição na formação dos enfermeiros em nível de pós graduação.

Desde então, vários enfermeiros brasileiros têm utilizado a TIC em pesquisas para averiguar e esclarecer ocorrências tanto na gestão como na assistência em saúde. Um autor ${ }^{(31)}$, na década de 1980, utilizou a TIC para verificar a satisfação no desempenho profissional do enfermeiro, estudando as necessidades psicossociais. Já na década de 1990, estudo de Chian$\mathrm{ca}^{(32)}$ analisou o transporte do paciente cirúrgico por meio da TIC. Atualmente diversos temas são tratados com essa técnica, como a formação e pesquisa em educação ${ }^{(5,12)}$, indicadores de qualidade e políticas de gestão ${ }^{(8-10)}$, idosos ${ }^{(6,16)}$ e práticas clínicas $^{(7,14-15)}$.

\section{Síntese da revisão}

Os achados foram analisados de acordo com os conteúdos e categorizados em quatro grandes temas que emergiram da síntese do processo analítico. O Quadro 2 foi construído para integrar os achados, no qual se identifica autor/ano/país de origem, título, objetivos, processo analítico e resultados alcançados pelo estudo.

O quadro permite observar, de modo geral, como essa técnica tem sido utilizada pelos pesquisadores. Além disso, pode-se também observar que a TIC possibilita o alcance dos objetivos propostos nas pesquisas. No que se refere à análise, verificou-se as várias possibilidades de abordagem analítica, visto que Flanagan não propõe um método específico para a análise dos dados ${ }^{(3)}$.

Nos artigos analisados foi ressaltado pelos autores a praticidade, flexibilidade, eficiência e completude da TIC como método para coleta e análise dos dados ${ }^{(12,34,40)}$. De acordo com alguns autores ${ }^{(5,7,14,40)}$, essas características do método permite a percepção de vários aspectos, que vão além do objetivo proposto e favorece o alcance dos resultados. Alguns relatos ${ }^{(7,14)}$ ainda apontam que a identificação e a categorização das situações, comportamentos e consequências com polaridades positivas ou negativas, viabiliza a identificação clara e objetiva dos problemas, permitindo intervenções rápidas. Por essa razão, a técnica foi apontada como eficiente para o alcance dos objetivos pretendidos.

Com relação ao tipo de análise empregada nos artigos encontrados, ocorreu certa similaridade entre a maioria dos estudos, na qual $12(70,6 \%)$ artigos utilizaram análise qualitativa, com categorização segundo os três elementos da TIC (situação, comportamento e conseqüência) e posterior subcategorização dos elementos, seja em conjunto ou cada

\begin{tabular}{|c|c|c|c|c|}
\hline Autor/Ano & Título & Objetivo & Processo Analítico & Resultados \\
\hline $\begin{array}{l}\text { Moreira RM; } \\
\text { Padilha KG /2001/ } \\
\text { Brasil }\end{array}$ & $\begin{array}{l}\text { Ocorrências iatrogênicas } \\
\text { com pacientes submetidos } \\
\text { à ventilaçäo mecânica } \\
\text { em Unidade de Terapia } \\
\text { Intensiva(21) }\end{array}$ & $\begin{array}{l}\text { Analisar as ocorrências } \\
\text { iatrogênicas no decorrer da } \\
\text { assistência de enfermagem } \\
\text { a pacientes intubados } \\
\text { ou traqueostomizados } \\
\text { submetidos à ventilação } \\
\text { mecânica na unidade de } \\
\text { terapia intensiva }\end{array}$ & $\begin{array}{l}\text { Análise qualitativa } \\
\text { e quantitativa, } \\
\text { categorização e } \\
\text { subcategorização } \\
\text { segundo os três } \\
\text { elementos da TIC }\end{array}$ & $\begin{array}{l}\text { O estudo verificou } \\
\text { a ocorrência de } 96 \\
\text { comportamentos } \\
\text { críticos negativos, } \\
\text { o que resultou em } \\
146 \text { consequências } \\
\text { relacionadas à } \\
\text { iatrogenias com } \\
\text { pacientes. }\end{array}$ \\
\hline $\begin{array}{l}\text { Carvalho VT; } \\
\text { Cassiani SHB } \\
\text { /2000/Brasil }\end{array}$ & $\begin{array}{l}\text { Erros na medicaçäo: análise } \\
\text { das situaçöes relatadas } \\
\text { pelos profissionais de } \\
\text { enfermagem } \\
(33)\end{array}$ & $\begin{array}{l}\text { Analisar as situações } \\
\text { que conduziram } \\
\text { os profissionais de } \\
\text { enfermagem aos erros } \\
\text { na administração de } \\
\text { medicamentos, com } \\
\text { base em relatos de erros } \\
\text { ocorridos }\end{array}$ & $\begin{array}{l}\text { Análise qualitativa, } \\
\text { categorização e } \\
\text { subcategorização } \\
\text { segundo o } \\
\text { elemento da TIC - } \\
\text { situação }\end{array}$ & $\begin{array}{l}\text { O estudo identificou } \\
\text { quatro categorias de } \\
\text { situações de riscos } \\
\text { que conduziram à } \\
\text { ocorrência de erros } \\
\text { na administração de } \\
\text { medicamentos. }\end{array}$ \\
\hline $\begin{array}{l}\text { Costa RS; Nogueira } \\
\text { LT /2008/Brasil }\end{array}$ & $\begin{array}{l}\text { Contribuição familiar no } \\
\text { controle da hipertensão } \\
\text { arterial( }^{(34)}\end{array}$ & $\begin{array}{l}\text { Analisar se a família do } \\
\text { hipertenso contribui } \\
\text { positivamente para o } \\
\text { controle de sua pressão } \\
\text { arterial }\end{array}$ & $\begin{array}{l}\text { Análise qualitativa, } \\
\text { categorização e } \\
\text { subcategorização } \\
\text { segundo o } \\
\text { elemento da TIC - } \\
\text { consequência }\end{array}$ & $\begin{array}{l}\text { O estudo identificou } \\
\text { que o envolvimento dos } \\
\text { familiares contribuiu } \\
\text { no tratamento do } \\
\text { hipertenso. }\end{array}$ \\
\hline $\begin{array}{l}\text { Aveyard } \mathrm{H} ; \\
\text { Woolliams M } \\
\text { /2006/Inglaterra }\end{array}$ & $\begin{array}{l}\text { In whose best interests? } \\
\text { Nurses' experiences of the } \\
\text { administration of sedation } \\
\text { in general medical wards } \\
\text { in England: an application } \\
\text { of the critical incident } \\
\text { technique }^{(19)}\end{array}$ & $\begin{array}{l}\text { Apresentar um relatório } \\
\text { sobre dados qualitativos } \\
\text { sobre a utilização da } \\
\text { sedação pelos enfermeiros }\end{array}$ & $\begin{array}{l}\text { Análise e } \\
\text { codificação } \\
\text { utilizando o } \\
\text { método da } \\
\text { constante } \\
\text { comparação } \\
\text { segundo Lincoln e } \\
\text { Cuba (1985) }\end{array}$ & $\begin{array}{l}\text { O estudo identificou } \\
\text { que os enfermeiros } \\
\text { estão preocupados com } \\
\text { a administração das } \\
\text { medicações utilizadas } \\
\text { para a sedação. }\end{array}$ \\
\hline
\end{tabular}




\begin{tabular}{|c|c|c|c|c|}
\hline $\begin{array}{l}\text { Bormann JE; Oman } \\
\text { D; Kemppainen JK; } \\
\text { Becker S; Gershwin } \\
\text { M; Kelly A /2006/ } \\
\text { Inglaterra }\end{array}$ & $\begin{array}{l}\text { Mantram repetition for stress } \\
\text { management in veterans } \\
\text { and employees: a critical } \\
\text { incident study }{ }^{(35)}\end{array}$ & $\begin{array}{l}\text { Avaliar a utilidade de um } \\
\text { programa de repetição de } \\
\text { mantra }\end{array}$ & $\begin{array}{l}\text { Análise qualitativa, } \\
\text { categorização e } \\
\text { subcategorização } \\
\text { segundo o } \\
\text { elemento da TIC - } \\
\text { situação }\end{array}$ & $\begin{array}{l}\text { O estudo concluiu } \\
\text { que o programa } \\
\text { mantra foi útil em uma } \\
\text { variedade de situações } \\
\text { relacionadas a que?? }\end{array}$ \\
\hline $\begin{array}{l}\text { Silva SC; Padilha } \\
\text { KG /2000/Brasil }\end{array}$ & $\begin{array}{l}\text { Parada cardiorrespiratória na } \\
\text { unidade de terapia intensiva: } \\
\text { análise das ocorrências } \\
\text { iatrogênicas durante o } \\
\text { atendimento }^{(22)}\end{array}$ & $\begin{array}{l}\text { Caracterizar as ocorrências } \\
\text { iatrogênicas relacionadas } \\
\text { aos comportamentos } \\
\text { da equipe durante o } \\
\text { atendimento do paciente } \\
\text { em PCR na UTI e verificar } \\
\text { as ocorrências imediatas do } \\
\text { atendimento à PCR em que } \\
\text { ocorrências iatrogências } \\
\text { foram identificadas }\end{array}$ & $\begin{array}{l}\text { Análise qualitativa } \\
\text { e quantitativa } \\
\text { segundo Nogueira } \\
\text { (1988) com } \\
\text { categorização e } \\
\text { subcategorização } \\
\text { segundo os três } \\
\text { elementos da TIC }\end{array}$ & $\begin{array}{l}\text { O estudo identificou } \\
126 \text { relatos de } \\
\text { incidentes críticos } \\
\text { que identificaram } \\
\text { pontos importantes } \\
\text { no desenvolvimento } \\
\text { de ocorrências } \\
\text { iatrogênicas. }\end{array}$ \\
\hline $\begin{array}{l}\text { Andraus LMS; } \\
\text { Munari DB; Faria } \\
\text { RM; Souza ACS } \\
\text { /2007/Brasil }\end{array}$ & $\begin{array}{l}\text { Incidentes críticos segundo } \\
\text { os familiares de crianças } \\
\text { hospitalizadas }^{(23)}\end{array}$ & $\begin{array}{l}\text { Analisar os incidentes } \\
\text { críticos relatados por } \\
\text { familiares de crianças } \\
\text { hospitalizadas }\end{array}$ & $\begin{array}{l}\text { Análise qualitativa } \\
\text { segundo Bardin } \\
\text { (1979) com } \\
\text { categorização e } \\
\text { subcategorização } \\
\text { segundo os três } \\
\text { elementos da TIC }\end{array}$ & $\begin{array}{l}\text { O estudo permitiu uma } \\
\text { avaliação indireta do } \\
\text { serviço prestado, no } \\
\text { que tange aos aspectos } \\
\text { de infra-estrutura, } \\
\text { comunicação, conflito } \\
\text { e enfrentamento. }\end{array}$ \\
\hline $\begin{array}{l}\text { Carvalho VT; } \\
\text { Cassiani SHB } \\
\text { /2002/Brasil }\end{array}$ & $\begin{array}{l}\text { Análise dos comportamentos } \\
\text { dos profissionais de } \\
\text { enfermagem frente aos } \\
\text { erros na administração de } \\
\text { medicamentos }^{(36)}\end{array}$ & $\begin{array}{l}\text { Analisar os } \\
\text { comportamentos } \\
\text { dos profissionais de } \\
\text { enfermagem com base em } \\
\text { relatos de erros ocorridos } \\
\text { na administração de } \\
\text { medicamentos }\end{array}$ & $\begin{array}{l}\text { Análise qualitativa, } \\
\text { categorização e } \\
\text { subcategorização } \\
\text { segundo o } \\
\text { elemento da TIC - } \\
\text { comportamento }\end{array}$ & $\begin{array}{l}\text { O estudo concluiu } \\
\text { que a maioria dos } \\
\text { enfermeiros percebeu } \\
\text { e comunicou o erro } \\
\text { imediatamente e após a } \\
\text { ocorrência do mesmo. }\end{array}$ \\
\hline $\begin{array}{l}\text { Carlucci VDS; Rossi } \\
\text { LA; Ficher AMFT; } \\
\text { Ferreira E; Carvalho } \\
\text { EC /2007/Brasil }\end{array}$ & $\begin{array}{l}\text { A experiência da } \\
\text { queimadura na perspectiva } \\
\text { do paciente }\end{array}$ & $\begin{array}{l}\text { Identificar as situações } \\
\text { vivenciadas por pacientes } \\
\text { queimados, percebidas por } \\
\text { eles durante a internação } \\
\text { como significantes, e } \\
\text { identificar os sentimentos e } \\
\text { conseqüências decorrentes } \\
\text { das situações relatadas }\end{array}$ & $\begin{array}{l}\text { Análise qualitativa, } \\
\text { categorização e } \\
\text { subcategorização } \\
\text { segundo os três } \\
\text { elementos da TIC }\end{array}$ & $\begin{array}{l}\text { O artigo identificou as } \\
\text { principais situações, } \\
\text { sentimentos e } \\
\text { consequências } \\
\text { relatadas como } \\
\text { significantes pelos } \\
\text { pacientes que sofreram } \\
\text { queimaduras. }\end{array}$ \\
\hline $\begin{array}{l}\text { Decesaro MN; } \\
\text { Padilha KG /2002/ } \\
\text { Brasil }\end{array}$ & $\begin{array}{l}\text { latrogenia na assistência } \\
\text { de enfermagem durante } \\
\text { internação em UTI: queda } \\
\text { de pacientes }^{(25)}\end{array}$ & $\begin{array}{l}\text { Explorar e descrever a } \\
\text { magnitude das ocorrências } \\
\text { iatrogênicas relacionadas } \\
\text { com a queda de pacientes } \\
\text { durante o período de } \\
\text { internação em UTI }\end{array}$ & $\begin{array}{l}\text { Análise qualitativa } \\
\text { e quantitativa, } \\
\text { categorização e } \\
\text { subcategorização } \\
\text { segundo os três } \\
\text { elementos da TIC }\end{array}$ & $\begin{array}{l}\text { Foram encontrados } \\
\text { no estudo } 90 \text { relatos } \\
\text { que possibilitaram } \\
\text { categorizar as situações, } \\
\text { comportamentos e } \\
\text { as conseqüências } \\
\text { imediatas para os } \\
\text { pacientes relacionadas } \\
\text { à queda. }\end{array}$ \\
\hline $\begin{array}{l}\text { Pupulim JSL; } \\
\text { Sawada NO /2005/ } \\
\text { Brasil }\end{array}$ & $\begin{array}{l}\text { Exposição corporal do } \\
\text { cliente no atendimento } \\
\text { das necessidades básicas } \\
\text { em UTI: incidentes críticos } \\
\text { relatados por enfermeiras }\end{array}$ & $\begin{array}{l}\text { Identificar e analisar } \\
\text { situações envolvendo } \\
\text { a exposição corporal e } \\
\text { invasão da privacidade } \\
\text { do cliente, inerentes à } \\
\text { assistência em UTI }\end{array}$ & $\begin{array}{l}\text { Análise qualitativa, } \\
\text { categorização e } \\
\text { subcategorização } \\
\text { segundo os três } \\
\text { elementos da TIC }\end{array}$ & $\begin{array}{l}\text { Os achados consistiram } \\
\text { em } 30 \text { relatos que } \\
\text { foram compilados em } \\
6 \text { categorias relativas } \\
\text { ao preparo adequado } \\
\text { da enfermagem para } \\
\text { lidar com assuntos } \\
\text { relacionados à } \\
\text { exposição corporal do } \\
\text { cliente. }\end{array}$ \\
\hline $\begin{array}{l}\text { Zani AV; Nogueira } \\
\text { MS /2006/Brasil }\end{array}$ & $\begin{array}{l}\text { Incidentes críticos } \\
\text { do processo ensino- } \\
\text { aprendizagem do curso de } \\
\text { graduação em enfermagem, } \\
\text { segundo a percepção de } \\
\text { alunos e docentes }\end{array}$ & $\begin{array}{l}\text { Identificar os fatores que } \\
\text { interferem positiva ou } \\
\text { negativamente no processo } \\
\text { ensino-aprendizagem, } \\
\text { segundo a visão de alunos } \\
\text { e professores do curso de } \\
\text { graduação em Enfermagem } \\
\text { da Universidade Norte do } \\
\text { Paraná - UNOPAR. }\end{array}$ & $\begin{array}{l}\text { Análise qualitativa, } \\
\text { categorização e } \\
\text { subcategorização } \\
\text { segundo os três } \\
\text { elementos da TIC }\end{array}$ & $\begin{array}{l}\text { O trabalho identificou } \\
\text { aspectos negativos e } \\
\text { positivos relacionados } \\
\text { ao processo ensino- } \\
\text { aprendizagem do } \\
\text { curso de enfermagem, } \\
\text { enfatizando a conduta } \\
\text { docente. }\end{array}$ \\
\hline $\begin{array}{l}\text { Carvalho VT; } \\
\text { Cassiani SHB } \\
\text { /2002/Brasil }\end{array}$ & $\begin{array}{l}\text { Erros na medicacão e } \\
\text { conseqüências para } \\
\text { profissionais de enfermagem } \\
\text { e clientes: um estudo } \\
\text { exploratório }^{(37)}\end{array}$ & $\begin{array}{l}\text { Analisar as conseqüências } \\
\text { de erros ocorridos para os } \\
\text { pacientes e profissionais de } \\
\text { enfermagem com base em } \\
\text { relatos de erros. }\end{array}$ & $\begin{array}{l}\text { Análise qualitativa, } \\
\text { categorização e } \\
\text { subcategorização } \\
\text { segundo o } \\
\text { elemento da TIC - } \\
\text { consequência }\end{array}$ & $\begin{array}{l}\text { Os dados obtidos } \\
\text { permitiram a } \\
\text { identificação das } \\
\text { conseqüências dos } \\
\text { erros de medicação } \\
\text { relacionadas ao } \\
\text { paciente e ao } \\
\text { profissional envolvido. }\end{array}$ \\
\hline
\end{tabular}




\begin{tabular}{|c|c|c|c|c|}
\hline $\begin{array}{l}\text { Decesaro MN; } \\
\text { Padilha KG /2001/ } \\
\text { Brasil }\end{array}$ & $\begin{array}{l}\text { Queda: comportamentos } \\
\text { negativos de enfermagem } \\
\text { e conseqüências para o } \\
\text { paciente durante o período } \\
\text { de internamento em UTI }{ }^{(38)}\end{array}$ & $\begin{array}{l}\text { Verificar os } \\
\text { comportamentos negativos } \\
\text { da equipe de enfermagem } \\
\text { e as conseqüências } \\
\text { imediatas para os pacientes } \\
\text { relacionados com a queda } \\
\text { durante o período de } \\
\text { internação em UTI }\end{array}$ & $\begin{array}{l}\text { Análise qualitativa } \\
\text { e quantitativa } \\
\text { segundo Nogueira } \\
\text { (1988) com } \\
\text { categorização e } \\
\text { subcategorização } \\
\text { segundo o } \\
\text { elemento da TIC - } \\
\text { comportamento }\end{array}$ & $\begin{array}{l}\text { Foram obtidos um } \\
\text { total de } 90 \text { relatos, } \\
\text { distribuídos em } \\
\text { nove categorias de } \\
\text { comportamentos } \\
\text { negativos e "deixar } \\
\text { o paciente só, sem } \\
\text { vigilância se destacou } \\
\text { nos resultados }\end{array}$ \\
\hline $\begin{array}{l}\text { Galvão CM; } \\
\text { Sawada NO; Castro } \\
\text { AP; Corniani F } \\
\text { /2000/Brasil }\end{array}$ & $\begin{array}{l}\text { Liderança e comunicação: } \\
\text { estratégias essenciais } \\
\text { para o gerenciamento da } \\
\text { assistência de enfermagem } \\
\text { no contexto hospitalar }{ }^{(28)}\end{array}$ & $\begin{array}{l}\text { Relatar um programa de } \\
\text { Educação Continuada } \\
\text { desenvolvido com } \\
\text { enfermeiros de um } \\
\text { hospital privado sobre } \\
\text { liderança e comunicação e } \\
\text { apresentar a aplicação da } \\
\text { Liderança Situacional na } \\
\text { prática profissional destes } \\
\text { profissionais. }\end{array}$ & $\begin{array}{l}\text { Análise qualitativa } \\
\text { e quantitativa, } \\
\text { categorização e } \\
\text { subcategorização } \\
\text { segundo os três } \\
\text { elementos da TIC }\end{array}$ & $\begin{array}{l}\text { Os sujeitos } \\
\text { participantes do } \\
\text { estudo avaliaram } \\
\text { positivamente as } \\
\text { contribuições oriundas } \\
\text { do programa e } \\
\text { também constataram } \\
\text { a viabilidade } \\
\text { de aplicação da } \\
\text { Liderança Situacional } \\
\text { no cotidiano da } \\
\text { enfermagem. }\end{array}$ \\
\hline $\begin{array}{l}\text { Andersson BT; } \\
\text { Fridlund B; Elgán C; } \\
\text { Axelsson AB /2008/ } \\
\text { Suécia }\end{array}$ & $\begin{array}{l}\text { Radiographers' areas of } \\
\text { professional competence } \\
\text { related to good nursing } \\
\text { care }^{(39)}\end{array}$ & $\begin{array}{l}\text { Descrever as áreas de } \\
\text { competência profissional } \\
\text { do radiologista em relação } \\
\text { aos bons cuidados de } \\
\text { enfermagem, baseada na } \\
\text { TIC que ocorrem no curso } \\
\text { de exames radiológicos e } \\
\text { intervenções. }\end{array}$ & $\begin{array}{l}\text { Análise qualitativa, } \\
\text { categorização e } \\
\text { subcategorização } \\
\text { segundo o } \\
\text { elemento da TIC - } \\
\text { comportamento }\end{array}$ & $\begin{array}{l}\text { O estudo destacou } \\
\text { as diferentes áreas do } \\
\text { competência exclusiva } \\
\text { do profissional } \\
\text { radiologista, bem } \\
\text { como destacou sua } \\
\text { importância. }\end{array}$ \\
\hline $\begin{array}{l}\text { Silén-Lipponen } \\
\text { M; Tossavainen K; } \\
\text { Turunen H; Smith A } \\
\text { /2004/Inglaterra }\end{array}$ & $\begin{array}{l}\text { Learning about teamwork } \\
\text { in operating room clinical } \\
\text { placement }^{(20)}\end{array}$ & $\begin{array}{l}\text { Descrever a natureza } \\
\text { do trabalho em equipe } \\
\text { experenciado pelos } \\
\text { estudantes de enfermagem } \\
\text { finlandeses, americanos e } \\
\text { britânicos durante estágios } \\
\text { clínicos. }\end{array}$ & $\begin{array}{l}\text { Os dados foram } \\
\text { analisados usando } \\
\text { um aplicativo } \\
\text { do método } \\
\text { fenomenológico } \\
\text { descritivo } \\
\text { desenvolvido por } \\
\text { Giorgi (1985, } \\
\text { 1992). }\end{array}$ & $\begin{array}{l}\text { O estudo concluiu que } \\
\text { o trabalho em equipe } \\
\text { pode eventualmente } \\
\text { ser utilizado no } \\
\text { desenvolvimento } \\
\text { de orientação de } \\
\text { estratégias e de gestão. }\end{array}$ \\
\hline
\end{tabular}

Quadro 2 - Quadro síntese dos artigos incluídos na revisão integrativa, segundo autor, ano, país de origem, título, objetivo, processo analítico e resultados. Goiânia-GO, 2010.

elemento dissociado. Há de se ressaltar que três desses artigos associaram análise quantitativa das categorias para melhor compreensão dos dados.

Esta análise encontra subsídio nos estudos de Dela Coleta, nos quais preconiza sete passos na utilização da TIC: 1) determinação dos objetivos da atividade que se deseja estudar; 2) elaboração das questões a serem apresentadas aos sujeitos que deverão fornecer os incidentes críticos da atividade em estudo; 3) delimitação da população ou amostra dos sujeitos a serem entrevistados; 4) coleta dos incidentes críticos; 5) análise do conteúdo dos incidentes coletados, buscando isolar os comportamentos críticos emitidos; 6) agrupamento dos comportamentos críticos em categorias mais abrangentes; 7) levantamento de frequências dos comportamentos positivos e/ou negativos que vão fornecer, posteriormente, uma série de indícios para identificação de soluções para situações problemáticas ${ }^{(30)}$.

Há autores ${ }^{(4)}$ que propõem a análise e categorização dos dados coletados pela TIC, por meio de uma ficha, na qual se distingue situação, comportamento e as inferências do pesquisador. Esses autores colocaram a categorização e análise segundo os mesmos critérios de qualquer análise de conteúdo, exemplificando a síntese dos incidentes como traços salientes do comportamento. Indica ainda a validação da análise por meio de confronto da categorização pela mesma pessoa após intervalo de tempo e por pessoas diferentes para calcular o índice de concordância, por exemplo: dividindo-se os acordos pela soma do $\mathrm{n}^{\circ}$ de acordos e desacordos.

Cinco artigos $(29,4 \%)$ utilizaram a TIC para a coleta dos dados e analisaram conforme os seguintes métodos: método da comparação constante, análise de conteúdo, análise fenomenológica e análise qualitativa e quantitativa conforme descrito no quadro acima.

Do conjunto da análise dos artigos distribuídos nos grupos apresentados ainda pode-se verificar que a área temática mais predominante nas publicações foi Enfermagem em Unidade de Terapia Intensiva com cinco $(29,4 \%)$ artigos, seguida da Enfermagem e administração de medicamentos com quatro $(23,5 \%)$ publicações e da Enfermagem Geral e especializada com três $(17,6 \%)$ artigos. A Enfermagem e Serviço de Assistência ao paciente tiveram duas $(11,7 \%)$ publicações e as demais áreas apenas uma publicação em cada. Seu uso nas diversas áreas da enfermagem é explicado pela eficiência dos resultados que a TIC alcança.

No que tange às áreas de conhecimento em que se utiliza a TIC e o conteúdo explorado pelos artigos incluídos no estudo, esses foram distribuídos em quatro categorias: análise de iatrogenias $(41,0 \%)$; avaliação de serviços $(35,4 \%)$; avaliação 
de vivências/experiências $(17,6 \%)$ e avaliação do processo ensino-aprendizagem $(6,0 \%)$.

\section{Análise de iatrogenias}

Foram incluídos no grupo "Análise de iatrogenias" sete $(41 \%)$ artigos que exploram temas como, por exemplo, erros de medicação, ocorrência de quedas, iatrogenias de forma geral. Segundo autor ${ }^{(6)}$ a caracterização das iatrogenias por meio da TIC revelam dados importantes que permite um redirecionamento da atenção à saúde, consequentemente melhorando a qualidade da assistência prestada.

Autores $^{(12)}$ afirmam que a TIC é uma importante ferramenta para a enfermagem, principalmente por possibilitar a observação de detalhes relacionados à prática assistencial, destacando a importância de investigar ações e comportamentos utilizando esta técnica com o objetivo de promover a inovação profissional e clínica dando a oportunidade de refletir e descrever os resultados da prática.

A análise de iatrogenias na assistência e a avaliação de serviços de saúde são questões atuais que envolvem a qualidade e a segurança expressas pelas organizações. Os artigos incluídos nesse grupo revelaram tal preocupação e apontaram por meio dos relatos das ocorrências, pistas que podem ser utilizadas na gestão dos serviços para solucionar ou permitir reflexões entre os profissionais, que por sua vez vão trazer impactos positivos para a prática.

\section{Avaliação de serviços}

Nesse grupo foram incluídos seis $(35,4 \%)$ artigos que trataram da avaliação de serviços prestados à saúde. Esses utilizaram a TIC para aferir o cuidado prestado, e corroborando com esses dados, estudo ${ }^{(10)}$ que utilizou a TIC para analisar a sustentabilidade de uma política de saúde afirmou que essa técnica foi eficaz pela facilidade na identificação dos eventos críticos relacionados à essa temática. Outros autores ${ }^{(8)}$ fizeram um estudo buscando indicadores qualitativos de gestão e refere que a técnica de incidentes críticos favoreceu a percepção acerca da melhoria das práticas visando o desenvolvimento de resultados organizacionais satisfatórios.

Outro dado semelhante foi destacado na pesquisa de Ribas $^{(14)}$ em 2008 que analisou o processo de ensino-aprendizagem em pacientes com diabetes na perspectiva da equipe multiprofissional de saúde e trouxe contribuições para sua área de pesquisa, pois permitiu verificar os fatores que contribuíam positivamente e negativamente para a educação em diabetes.

Alguns autores ${ }^{(40)}$, em 2008, referem que a TIC permitiu a identificação dos entraves referentes aos serviços oferecidos por um posto de atendimento de Santa Catarina, o que ofereceu subsídios para a melhoria do serviço prestado.

A avaliação de serviços é um tema que exige a utilização de ferramentas que permitam objetividade e rapidez no diagnóstico de situações criticas, com vistas a desenvolver intervenções possíveis para se promover mudanças que reflitam na melhoria da prática. Por essa razão a TIC se mostra eficaz para responder questões pertinentes à dinâmica do trabalho.

\section{Avaliação de vivências/experiências}

Nesse grupo foram reunidos três $(17,6 \%)$ artigos que descrevem a avaliação de vivências/experiências de pacientes e profissionais frente a determinadas situações. Na perspectiva de autores ${ }^{(12)}$ a TIC é útil para apreendermos as vivências e experiências de pacientes e profissionais, envolvendo comportamentos, cuidados em relação à dor, adesão ao tratamento, relacionamentos com a equipe de saúde, medidas de prevenção e promoção da saúde, dentre outros.

Martins e Carvalho ${ }^{(7)}$ referem que o reconhecimento do valor dessa metodologia se deve à sua capacidade para explicar a percepção de pacientes sobre os cuidados de saúde e os sentimentos experimentados por esta clientela.

$\mathrm{O}$ uso da TIC em estudos relacionados à avaliação de vivências e experiências tanto de pacientes como de profissionais permite analisar e avaliar a eficácia do trabalho exercido pela equipe, pois a compreensão do processo vivido pelas pessoas nas diversas situações do cuidado em saúde é fundamental para possibilitar novas abordagens que atendam suas reais necessidades.

\section{Avaliação do processo ensino-aprendizagem}

Nesse grupo foi incluído um $(6,0 \%)$ artigo ${ }^{(27)}$ que trata da avaliação do processo ensino-aprendizagem no curso de graduação em enfermagem.

$\mathrm{Na}$ área da educação essa técnica também se apresenta como uma importante ferramenta de mensuração do processo ensino-aprendizagem. O uso da TIC pode auxiliar a compreensão das situações que afetam a construção do conhecimento prático do aluno e conhecer o significado da sua experiência de aprendizagem, promovendo o exercício reflexivo(12).

Estrela e Estrela ${ }^{(4)}$ já discutiam o uso dessa técnica para esse fim, afirmando que a aplicação da TIC no ensino é eficiente devido a sua simplicidade e operacionalidade. Autor ${ }^{(5)}$ corrobora com as opiniões de Estrela e Estrela ${ }^{(4)}$ e ainda afirma que essa técnica tem um grande potencial na área do ensino por ser um bom instrumento para a formação e a pesquisa em educação ${ }^{(5)}$.

Em suma, pode-se dizer que a utilização da TIC na pesquisa em enfermagem possibilita reflexão e descrição de situações práticas de enfermagem; compreensão dos diferentes papéis assumidos pelos enfermeiros nas diversas atividades e processos realizados; prática reflexiva no processo de ensino em enfermagem; análise dos indicadores de qualidade de atendimento; subsídio para melhorias no funcionamento dos serviços de saúde, para determinar quais as lacunas ou áreas críticas que ocorrem no cuidado de enfermagem.

Há de se ressaltar nesse estudo a afirmação de que a identificação dos incidentes críticos é um elemento chave para a tomada de decisão tanto dos sujeitos envolvidos na pesquisa quanto do próprio pesquisador, por levar a reflexão baseada em dados concretos e objetivos ${ }^{(5)}$. Esse processo se constitui em um momento rico de formação, pois provoca a reflexão sobre o que aconteceu com o outro, e sobre sua trajetória, levando o pesquisador a refletir sobre sua própria atuação e trajetória profissional(5). 


\section{CONSIDERAÇÕES FINAIS}

Tendo em vista o objetivo inicial de sintetizar o conhecimento produzido nas pesquisas em enfermagem que utilizaram a técnica de incidente crítico, os resultados permitiram evidenciar que o Brasil é o país que mais desenvolve pesquisa utilizando a TIC como método de coleta e análise de dados, seguido da Inglaterra e Suécia. Em relação às bases de dados, a LILACS se destacou comparada às demais (MEDLINE e SciELO). Os anos de publicação mais predominantes foram 2000, 2002 e 2006. Quanto aos periódicos houve predominância da "Revista Latino-americana de Enfermagem", seguido da "Acta Paulista de Enfermagem" e "Revista da Escola de Enfermagem da USP".

A maioria dos artigos utilizou a análise qualitativa, com categorização segundo os três componentes da TIC (situação, comportamento e consequência) e posterior subcategorização dos elementos. A subárea da enfermagem que se apresentou com maior número de artigos publicados nessa temática foi Enfermagem em Unidade de Terapia Intensiva.

A TIC tem sido mais utilizada na enfermagem para analisar iatrogenias na assistência em saúde e avaliação dos serviços de saúde e os resultados dos estudos apontam sua eficiência nesse processo. Os objetivos apresentados pelos autores dos artigos estudados permitiram a observação de que esses foram pertinentes ao uso da metodologia que traz exigência crítica suficiente para propor alterações na prática e melhorar a qualidade e a segurança da assistência em saúde.

A revisão integrativa realizada possibilitou a construção de uma síntese do conhecimento científico sobre o uso da TIC por pesquisadores da Enfermagem. Entretanto, vale ressaltar que o critério de inclusão de se realizar a busca somente de artigos via on line apresentou-se como uma limitação do estudo.

Após analisar os artigos que utilizaram a TIC como método de coleta de dados, percebeu-se que a sua aplicação é objetiva e eficaz, pois traz situações e comportamentos identificados como críticos, o que permite a reflexão de possíveis soluções para a melhoria do atendimento e da qualidade da assistência prestada.

Conclui-se que o uso da TIC pela enfermagem, pela sua eficácia na resolução de problemas do cotidiano da prática assistencial e das relações humanas, possibilita análise aprofundada de fatores que interferem diretamente no cuidado prestado, bem como fortalece a construção do conhecimento da enfermagem e a qualidade da assistência à saúde.

\section{REFERÊNCIAS}

1. Salles EB, Barreira IA. Formação da comunidade científica de enfermagem no Brasil. Texto \& Contexto Enferm 2010;19(1):137-46.

2. Carvalho V. Sobre construtos epistemológicos nas ciências: uma contribuição para a enfermagem. Rev Latinoam Enferm 2003;11(4):420-8.

3. Flanagan J. The critical incident technique. Psychol Bul 1954;(51):327-58

4. Estrela MT, Estrela A. A técnica dos incidentes críticos no ensino. 2 ed. Lisboa: Estampa; 1994.

5. Almeida LR. O incidente crítico na formação e pesquisa em educação. Rev Educ Ling 2009;12(19):181-200.

6. Silva TM, Nakatani AYK, Souza ACS, Lima MCS. A vulnerabilidade do idoso para as quedas: análise dos incidentes críticos. Rev Eletrônica Enferm 2007;9(1):64-78.

7. Martins FTM, Carvalho EC. Patients' perception regarding the use of a long-term catheter. Rev Esc Enferm USP 2008;42(3):526-31.

8. Bulgacov S, Bulgacov YLM, Canhada DID. Indicadores qualitativos de gestão para incubadoras e empresas empreendedoras incubadas: um estudo longitudinal. FACES R Adm 2009;8(2):55-74.

9. Silva EM, Yue GK, Rotondaro RG, Laurindo FJB. Gestão da qualidade em serviços de TI: em busca de competitividade. Prod 2006;16(2):329-40.

10. Felisberto E, Freese E, Bezerra LC, Alves CK, Samico I.. Sustainability analysis of an evaluation policy: the case of primary health care in Brazil. Cad Saúde Publica 2010;26(6):1079-95.

11. Matheus MCC, Fustinoni SM. Pesquisa Qualitativa em Enfermagem. São Paulo: Livraria Médica Paulista Editora; 2006.

12. Pena ALN; Juan LC. La Técnica del Incidente Crítico y sus implicaciones en el desarrollo de la investigación en enfermería. Index Enferm 2008;17(1):48-52.

13. Carlucci VDS, Rossi LA, Ficher AMFT, Ferreira E, CarvaIho EC. Burn experiences from the patient's perspective. Rev Esc Enferm USP 2007;41(1):21-8.

14. Ribas CRP, Teixeira CRS, Oliveira VA, Martins TA, Mendes KDS, Santos MA et al. Incidentes críticos no processo de ensino-aprendizagem em diabetes na perspectiva da equipe multiprofissional de saúde. Rev Eletrônica Enferm 2008;10(3):747-55.

15. Simoes JFFL, Garrido AFS. Purpose of supervision strategies used in nursing clinical practice. Texto \& Contexto Enferm 2007;16(4):599-608.

16. Carvalhais $M$, Sousa L. Comportamentos dos enfermeiros e impacto em doentes idosos em situação de internamento hospitalar. Rev Eletrônica Enferm 2007;09(3):596-616.

17. Venancio LS, Nassif ME. O comportamento de busca de informação sob o enfoque da cognição situada: um estudo empírico qualitativo. Ciênc Inf 2008;37(1):95-106.

18. Volpato, G. L. Pérolas da Redação Científica. 1. ed. São Paulo: Cultura Acadêmica; 2010. 189 p. 
19. Aveyard H; Woolliams M. In whose best interests? Nurses' experiences of the administration of sedation in general medical wards in England: an application of the critical incident technique. Int J Nurs Stud 2006;43(2006):929-39.

20. Silén-Lipponen $M$; Tossavainen $\mathrm{K}$; Turunen $\mathrm{H}$; Smith A. Learning about teamwork in operating room clinical placement. Br J Nurs 2004;13(5):244-54.

21. Moreira RM; Padilha KG. Ocorrências iatrogênicas com pacientes submetidos à ventilaçäo mecânica em Unidade de Terapia Intensiva. Acta Paul Enferm 2001;14(2):9-18.

22. Silva SC; Padilha KG. Parada cardiorrespiratória na unidade de terapia intensiva: análise das ocorrências iatrogênicas durante o atendimento. Rev Esc Enferm USP 2000;34(4):1-9.

23. Andraus LMS; Munari DB; Faria RM; Souza ACS. Incidentes críticos segundo os familiares de crianças hospitalizadas. Rev Enferm UERJ 2007;15(4):574-9.

24. Carlucci VDS; Rossi LA; Ficher AMFT; Ferreira E; CarvaIho EC. A experiência da queimadura na perspectiva do paciente. Rev Esc Enferm USP 2007;41(1):21-8.

25. Decesaro MN; Padilha KG. Iatrogenia na assistência de enfermagem durante internação em UTI: queda de pacientes. Ciênc Cuid Saúde 2002;1(1):159-62.

26. Pupulim JSL; Sawada NO. Exposição corporal do cliente no atendimento das necessidades básicas em UTI: incidentes críticos relatados por enfermeiras. Rev Latinoam Enferm 2005;13(3):388-96.

27. Zani AV; Nogueira MS. Incidentes críticos do processo ensino-aprendizagem do curso de graduação em enfermagem, segundo a percepção de alunos e docentes. Rev Latinoam Enferm 2006;14(5):98-106.

28. Galvão CM; Sawada NO; Castro AP; Corniani F. Liderança e comunicação: estratégias essenciais para o gerenciamento da assistência de enfermagem no contexto hospitalar. Rev Latinoam Enferm 2000;8(5):34-43.

29. Mendes KDS, Silveira RCCP, Galvão CM. Revisão integrativa: método de pesquisa para a incorporação de evidências na saúde e na enfermagem Texto \& Contexto Enferm 2008;17(4): 758-64.
30. Dela Coleta JA. A técnica dos incidentes críticos: aplicações e resultados. Arq Bras Psicol Apl 1974;26(2):35-58.

31. Di Lascio CMD. Satisfaçäo no desempenho profissional da enfermeira: estudo sobre necessidades psicossociais. Rev Esc Enferm USP 1980;14(3):321-31.

32. Chianca TCM. Uma visão sistêmica do transporte do paciente cirúrgico. Ribeirão Preto. Dissertação [Mestrado em Enfermagem] - Escola de Enfermagem de Ribeirão Preto/USP; 1992.

33. Carvalho VT; Cassiani SHB. Erros na medicaçäo: análise das situaçöes relatadas pelos profissionais de enfermagem. Med 2000;33:322-30.

34. Costa RS; Nogueira LT. Contribuição familiar no controle da hipertensão arterial. Rev Latinoam Enferm 2008;16(5):75-81.

35. Bormann JE; Oman D; Kemppainen JK; Becker S; Gershwin M; Kelly A. Mantram repetition for stress management in veterans and employees: a critical incident study. J Adv Nurs 2006;53(5): 502-12.

36. Carvalho VT; Cassiani SHB. Análise dos comportamentos dos profissionais de enfermagem frente aos erros na administração de medicamento. Acta Paul Enferm 2002;15(2):45-55.

37. Carvalho VT; Cassiani SHB. Erros na medicacão e conseqüências para profissionais de enfermagem e clientes: um estudo exploratório. Rev Latinoam Enferm 2002;10(4):523-9.

38. Decesaro MN; Padilha KG. Queda: comportamentos negativos de enfermagem e conseqüências para o paciente durante o período de internamento em UTI. Arq Ciências Saude UNIPAR 2001;5(2):115-21.

39. Andersson BT; Fridlund B; Elgán C; Axelsson AB.. Radiographers' areas of professional competence related to good nursing care. Scand J Caring Sci 2008;22:401-9.

40. Schroeder JB, latchac M. Análise de incidentes críticos: uso prático desta metodologia numa pesquisa de satisfação no atendimento dos serviços oferecidos na Viacredi. Rev Interdisciplin Cient Apl 2008;2(2):1-20. 